\title{
From Jackfruit Rags to Hierarchical Porous N-Doped Carbon: A High-Performance Anode Material for Sodium-Ion Batteries
}

\author{
Baisheng Zhao ${ }^{1,2} \cdot$ Yichun Ding $^{1} \cdot$ Zhenhai Wen $^{1}$
}

Received: 12 April 2019 / Revised: 6 May 2019 / Accepted: 8 May 2019 / Published online: 18 June 2019

(c) The Author(s) 2019

\begin{abstract}
Renewable biomass-derived carbon materials have attracted increasing research attention as promising electrode materials for electrochemical energy storage devices, such as sodium-ion batteries (SIBs), due to their outstanding electrical conductivity, hierarchical porous structure, intrinsic heteroatom doping, and environmental friendliness. Here, we investigate the potential of hierarchical N-doped porous carbon (NPC) derived from jackfruit rags through a facile pyrolysis as an anode material for SIBs. The cycling performance of NPC at $1 \mathrm{~A} / \mathrm{g}$ for 2000 cycles featured a stable reversible capacity of $122.3 \mathrm{~mA} \cdot \mathrm{h} / \mathrm{g}$ with an outstanding capacity retention of $99.1 \%$. These excellent electrochemical properties can be attributed to the unique structure of NPC; it features hierarchical porosity with abundant carbon edge defects and large specific surface areas. These results illuminate the potential application of jackfruit rags-derived porous carbon in SIBs.
\end{abstract}

Keywords Porous carbon $\cdot \mathrm{N}$-doped carbon $\cdot$ Sodium-ion battery $\cdot$ Anode $\cdot$ Jackfruit rags $\cdot$ Energy storage and conversion

\section{Introduction}

The serious issues of ever-increasing global warming and resource shortage have stimulated increasing attention on exploring novel energy storage and conversion technologies [1]. New energy sources such as solar, water, wind, and geothermal energy have been largely developed to solve the problems. However, these energy sources are intermittent and unpredictable and thus cannot provide a stable and continuous power supply. Storing the generated electrical energy in electrochemical energy storage devices is a promising route to maximize renewable energy utilization. Currently, rechargeable lithium-ion batteries (LIBs) with high energy density, long lifetime, and environmental benignity are

Yichun Ding

ycding@ jirsm.ac.cn

$\triangle$ Zhenhai Wen

wen@fjirsm.ac.cn

1 CAS Key Laboratory of Design and Assembly of Functional Nanostructures, Fujian Provincial Key Laboratory of Nanomaterials, Fujian Institute of Research on the Structure of Matter, Chinese Academy of Sciences, Fuzhou 350002, China

2 University of Chinese Academy of Sciences, Beijing 100049, China the most promising portable energy storage devices [2-4]. However, the high cost and uneven distribution of lithium minerals will restrict the large-scale commercial markets of electronic products and electric vehicles. In recent years, sodium-ion batteries (SIBs) have been widely revived as an intriguing alternative to LIBs for energy storage owing to the abundant distribution of sodium $(\mathrm{Na})$ resources in the earth and the similarity of sodium with lithium in physical/ chemical properties [5-7]. However, the poor kinetics of the $\mathrm{Na}^{+}$insertion/de-insertion reaction caused by the larger radius of $\mathrm{Na}^{+}(0.102 \mathrm{~nm})$ compared to $\mathrm{Li}^{+}(0.076 \mathrm{~nm})$ limits the development and practical applications of SIBs $[8,9]$. Therefore, seeking appropriate and efficient anode materials that are capable of reversible insertion/de-insertion of $\mathrm{Na}^{+}$ is essential to achieving the practical application of SIBs.

Carbonaceous materials represent the most widely used anode materials for various rechargeable batteries. One example is the commercial graphite; however, in the previous research, $\mathrm{Na}^{+}$could not be inserted into graphite in SIBs, indicating the thermodynamic electrochemical insertion of $\mathrm{Na}^{+}$into graphite is not possible [10,11]. Research on other carbonaceous materials has found that $\mathrm{Na}^{+}$is more inclined to be inserted into disordered layers of carbon [12, 13]. Moreover, it is worth noting that the electrochemical performance of carbonaceous materials can be enhanced through doping heteroatom elements and manufacturing 
porous structures $[14,15]$, which provides higher conductivity and extra Na-ion storage sites in SIBs [16-21]. Hence, in recent years, biomass-derived porous carbon has been extensively investigated as anode materials for SIBs [22] because of their advantages of high abundance, low cost, easy accessibility, environmental friendliness, hierarchical porous structure, and intrinsic heteroatom doping behavior. In addition, their high electrical conductivity and large electrolyte/electrode contact area are favorable to the reversible insertion and extraction of $\mathrm{Na}^{+}$, resulting in excellent and stable electrochemical performance [23]. Many types of biomass such as bamboo [24], water hyacinths [25], waste tea [26], corn stalk [27], wood [28, 29], lotus [30], kelp [31], and human hair [32] have been investigated as a precursor for producing porous carbon materials for various energy storage devices; however, it is still a challenge to prepare high-performance porous carbon from a cost-efficient resource.

Jackfruit (Artocarpus heterophyllus) is a tropical fruit that is widely planted in South and Southeast Asian countries. Jackfruit rags are latex-like filaments surrounding the edible part (fruit/aril), but they are typically deserted as a waste. Therefore, to reduce the waste and develop new value-added products, herein we employ the jackfruit rags as a precursor to produce porous carbon. Hierarchical N-doped porous carbon (NPC) was synthesized through a simple one-step carbonization of jackfruit rags without using any chemical or physical activation process. Moreover, jackfruit rags contain numerous alkaline earth elements $\left(\mathrm{Na}^{+}, \mathrm{K}^{+}, \mathrm{Ca}^{2+}, \mathrm{Mg}^{2+}\right)$ that could lead to self-activation during pyrolysis, which makes the carbon production process more environmentally friendly and low cost $[33,34]$. We evaluated the effectiveness of as-synthesized NPC as anode materials for SIBs, and they showed excellent electrochemical performance.

\section{Experimental}

\section{Preparation of N-Doped Porous Carbon}

The jackfruit rags were separated from jackfruits purchased from Thailand on Taobao.com and used as the biomass precursor. Figure 1 schematically illustrates the synthesis of $\mathrm{N}$-doped porous carbon from jackfruit rags. First, $5.0 \mathrm{~g}$ of jackfruit rags was dipped/washed in $200 \mathrm{~mL}$ of deionized (DI) water for $6 \mathrm{~h}$ to remove impurities. The obtained jackfruit rags were then dried in an oven at $80{ }^{\circ} \mathrm{C}$ overnight to completely remove water. Subsequently, carbonization process was performed in a furnace at three different temperatures (i.e., $700{ }^{\circ} \mathrm{C}, 800{ }^{\circ} \mathrm{C}$, and $900{ }^{\circ} \mathrm{C}$ ) with a heating rate of $10^{\circ} \mathrm{C} / \mathrm{min}$ and annealed for $2 \mathrm{~h}$ under argon (Ar) atmosphere. After cooling down to room temperature, the resulting samples were ground and washed by $0.2 \mathrm{~mol} / \mathrm{L} \mathrm{HCl}$

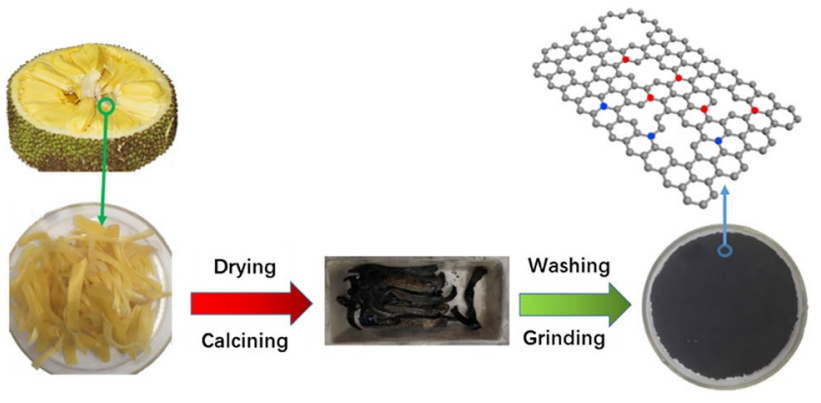

Fig. 1 Schematic illustration of the synthesis of N-doped porous carbon from jackfruit rags

solution for $12 \mathrm{~h}$ to completely remove minerals residues. The acid-washed samples were collected by filtration and washed repeatedly with DI water. Finally, the obtained black powder was dried overnight in a vacuum oven at $80^{\circ} \mathrm{C}$. The obtained jackfruit rags-derived porous carbons are denoted as NPC-700, NPC-800, and NPC-900.

\section{Characterization}

Thermogravimetric analysis (TGA, Netzsch STA 449) was performed to optimize the pyrolysis temperature of the biomass to obtain pyrolytic carbons. X-ray diffraction (XRD, MiniFlex600, Rigaku), X-ray photoelectron spectroscopy (XPS, Thermo Scientific ESCALAB 250Xi), and Raman spectroscopy (LabRAM HR, $532 \mathrm{~nm}$ laser) were used to examine the ingredients, element valence state environment, degree of crystallinity, and the intensity ratio of defect to graphitic carbon $\left(I_{\mathrm{D}} / I_{\mathrm{G}}\right)$. Porous characteristics such as the specific surface area, pore volume, and pore size distribution were analyzed on a Micromeritics ASAP 2020 adsorption analyzer. Pore size and distribution were determined by the Brunauer-Emmett-Teller (BET) method. Scanning electron microscopy (SEM, Nova NanoSEM450) and transmission electron microscopy (TEM, JEM-2010) were employed to investigate the microscopic shape and structure of carbon materials. The content of nitrogen element was determined using an elemental analyzer (EA, Vario EL Cube, Elementar).

\section{Electrochemical Performance}

The electrochemical performance of the biomass-derived carbons was investigated by assembling CR2032 coin cells. The anode materials of SIBs were made by mixing $80 \%$ NPC-700 (as well as NPC-800 and NPC-900) with 10\% Super P carbon black and $10 \%$ polyvinylidene fluoride to form a slurry and coating on a copper foil with an active mass loading of $\sim 1.0 \mathrm{mg} / \mathrm{cm}^{2}$ and then dried at $80{ }^{\circ} \mathrm{C}$ for $12 \mathrm{~h}$ under vacuum. Sodium metal foil was used as the 
counter and reference electrodes. Glass microfiber membrane (Grade GF/D, Whatman) was used as separator, and $1.0 \mathrm{~mol} / \mathrm{L} \mathrm{NaClO}_{4}$ dissolved in a mixture of propylene carbonate, ethylene carbonate, and fluoroethylene carbonate $(1: 1: 0.05 V / V / V)$ was used as electrolyte. All coin cells were assembled under argon atmosphere in a glovebox $\left(\mathrm{H}_{2} \mathrm{O}, \mathrm{O}_{2}<0.1 \mathrm{ppm}, \mathrm{MBraun}\right.$, Germany). The galvanostatic charge/discharge tests were carried out on a Land CT2001A tester between 3.00 and $0.01 \mathrm{~V}$. Cyclic voltammetry was conducted on an electrochemical workstation (CHI760E, China) at a scan rate of $0.1 \mathrm{mV} / \mathrm{s}$. Electrochemical impedance spectroscopy (EIS, Biologic, VSP) measurements were implemented in a frequency range of $0.01 \mathrm{~Hz}-100 \mathrm{kHz}$.

\section{Results and Discussion}

\section{Structure and Composition Characterization}

Thermogravimetric analysis was carried out to investigate the carbonization temperature of jackfruit rags. Figure $2 \mathrm{a}$ shows the TGA curve acquired under argon atmosphere. The weight loss below $230{ }^{\circ} \mathrm{C}$ is attributed to the volatilization of the remaining water in the fibrous channel of jackfruit rags. The rapid weight loss from around 230 to $700{ }^{\circ} \mathrm{C}$ can be ascribed to the evaporation of bonded water and decomposition of organic matters into $\mathrm{H}_{2} \mathrm{O}, \mathrm{CO}$, and $\mathrm{CO}_{2}$ volatile gases. The TGA curve became flat at above $700{ }^{\circ} \mathrm{C}$, indicating that a further decomposition process did not occur at this temperature range. The total weight loss was about $76 \%$, indicating a carbon yield of $24 \%$. Therefore, we synthesized a series of hierarchical NPC by pyrolyzing jackfruit rags under Ar atmosphere at diverse temperatures above $700{ }^{\circ} \mathrm{C}$ (including $700{ }^{\circ} \mathrm{C}, 800{ }^{\circ} \mathrm{C}$, and $900{ }^{\circ} \mathrm{C}$ ).

XPS was carried out to analyze the elemental composition of as-prepared carbonaceous materials. As depicted in Fig. 2b, the XPS spectra of NPCs featured three major peaks at around $284.7 \mathrm{eV}, 400 \mathrm{eV}$, and $532.5 \mathrm{eV}$, which correspond to $\mathrm{C} 1 \mathrm{~s}, \mathrm{~N} 1 \mathrm{~s}$, and $\mathrm{O} 1 \mathrm{~s}$, respectively. The elemental compositions are summarized in Table 1, and as seen, NPC-800 had the highest $\mathrm{N}$ content ( $2.6 \mathrm{wt} \%$ ) compared with the other two samples. Nitrogen doping will significantly improve the electrochemical performance of NPC-800, which can enhance the surface reactivity of Na-ion storage sites and increase the electronic conductivity of the carbon materials.

The microstructure was characterized by XRD and Raman spectroscopy (Fig. 3). The XRD patterns of NPCs (Fig. 3a) displayed two broad peaks at around $2 \theta$ angle of

Table 1 Result of nitrogen adsorption analysis and the mass of nitrogen obtained from elemental analysis

\begin{tabular}{llllll}
\hline Samples & $\begin{array}{l}S_{\text {BET }} \\
\left(\mathrm{m}^{2} / \mathrm{g}\right)\end{array}$ & $\begin{array}{l}V_{\mathrm{t}} \\
\left(\mathrm{cm}^{3} / \mathrm{g}\right)\end{array}$ & $\begin{array}{l}\text { Micropores } \\
(\%)\end{array}$ & $\begin{array}{l}\text { Mesopores } \\
(\%)\end{array}$ & $\begin{array}{l}\text { N content } \\
(\mathrm{wt} \%)\end{array}$ \\
\hline NPC-700 & 443.35 & 0.262 & 55.9 & 44.1 & 1.79 \\
NPC-800 & 957.30 & 0.887 & 50.1 & 49.9 & 2.60 \\
NPC-900 & 563.60 & 0.293 & 48.7 & 51.3 & 1.30 \\
\hline
\end{tabular}

Fig. 2 a TGA curve of dried jackfruit rags under argon atmosphere, b XPS survey scan of NPC-700, NPC-800, and NPC-900, c fine XPS spectra for N 1s of NPC-800, and d fine XPS spectra for $\mathrm{C} 1 \mathrm{~s}$ of NPC-800
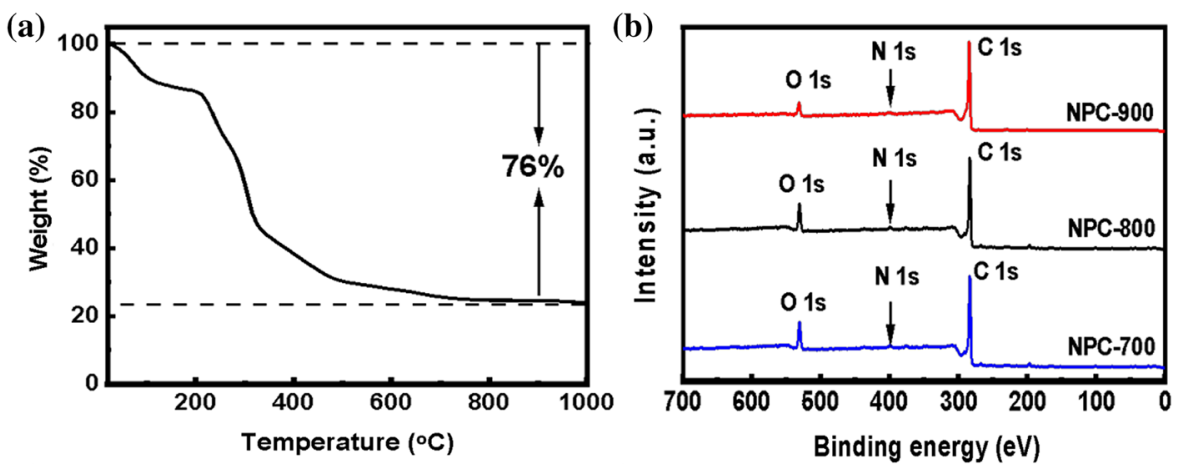

(c)

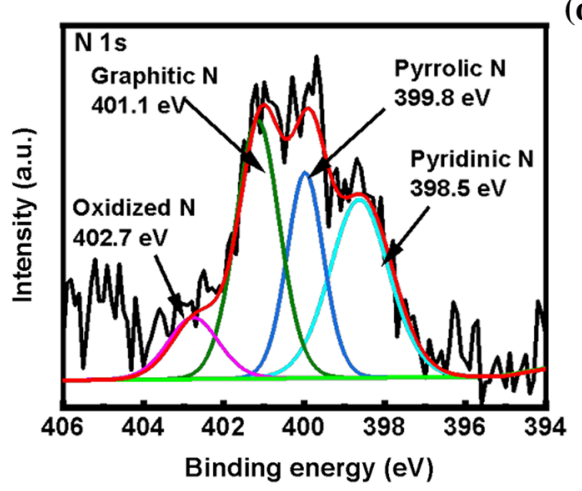


Fig. 3 a XRD patterns, b Raman spectra, $\mathbf{c} \mathrm{N}_{2}$ adsorption/ desorption isotherms, and $\mathbf{d}$ the pore size distribution curves of NPC-700, NPC-800, and NPC-900 (a)

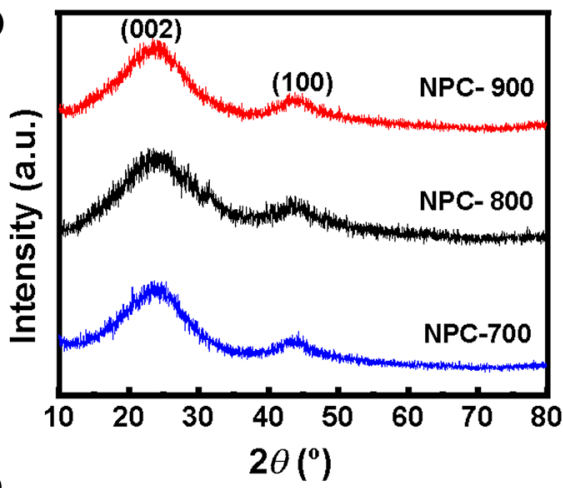

(c)

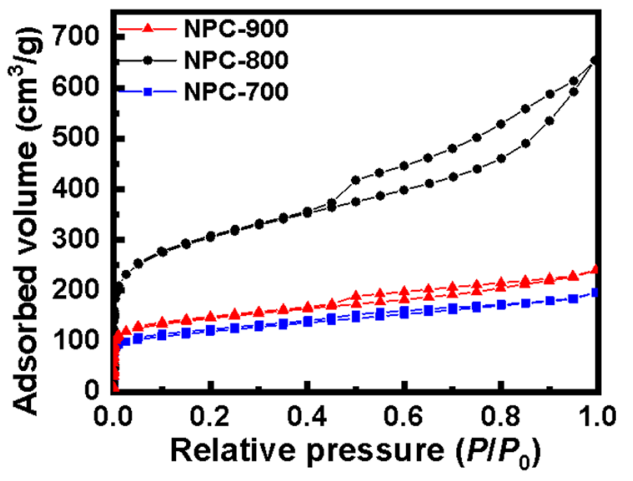

(b)

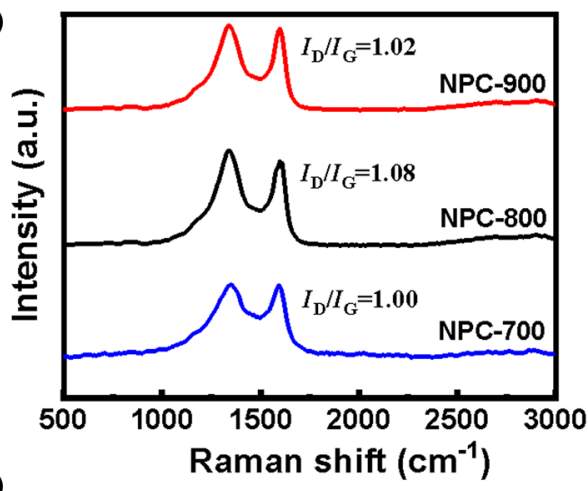

(d)

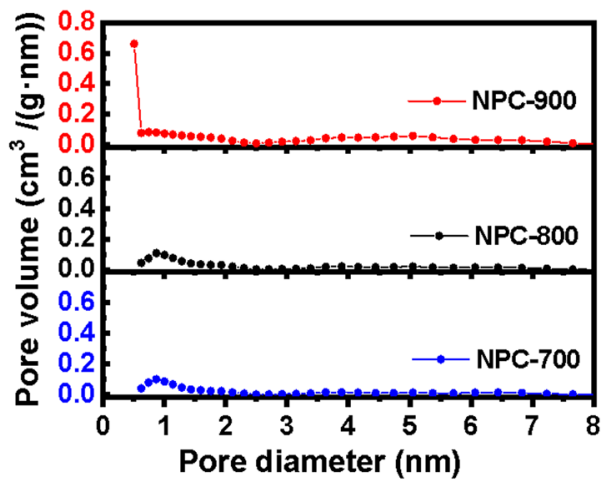

$23.5^{\circ}$ and $43.6^{\circ}$, respectively, corresponding to the (002) and (100) peak crystalline planes of graphite, typical for amorphous carbon. The interlayer spacing of graphitic layers calculated from the (002) peak using Bragg's law was $0.39 \mathrm{~nm}$, which agrees with the TEM result (will be discussed subsequently). The large interlayer spacing satisfies the reversible insertion/extraction of large-sized $\mathrm{Na}$ ion and is thus beneficial to the reversible storage of $\mathrm{Na}$ ion. The Raman spectra of NPCs are displayed in Fig. 3b; all NPCs showed two characteristic peaks at around $1334 \mathrm{~cm}^{-1}$ and $1596 \mathrm{~cm}^{-1}$, ascribed to the D peak and $G$ peak, respectively. The intensity ratio $I_{\mathrm{D}} / I_{\mathrm{G}}$ of NPC-800 was 1.08 , which was the largest among the three samples (NPC-700, $I_{\mathrm{D}} / I_{\mathrm{G}}=1.00$; NPC-900, $I_{\mathrm{D}} / I_{\mathrm{G}}=1.02$ ), revealing that the NPC-800 material had the most defects [35].

The specific surface area and pore size distribution of NPC samples were further detected, and the $\mathrm{N}_{2}$ adsorption-desorption isotherms are shown in Fig. 3c. As can be seen, the NPC-800 sample had the largest amount of adsorbed $\mathrm{N}_{2}$, suggesting its specific surface area was maximum. The specific surface areas of NPC-700, NPC-800, and NPC-900 were about $443.35 \mathrm{~m}^{2} / \mathrm{g}, 957.30 \mathrm{~m}^{2} / \mathrm{g}$, and $563.59 \mathrm{~m}^{2} / \mathrm{g}$, respectively, as analyzed by BET method. The $\mathrm{N}_{2}$ adsorption-desorption of all the three samples exhibited typical types I and IV isotherms (Fig. 3c) [36], indicating the typical characteristics of microporous and mesoporous materials [37]. These high specific surface areas are attributed to the intrinsic porous structure of biomass and the existence of myriads of alkaline earth elements, which will etch the carbon under high temperatures; such a "self-activation" process will produce numerous microporous and mesoporous pores [34]. The specific surface area increased when the pyrolysis temperature increased from 700 to $800{ }^{\circ} \mathrm{C}$, which may be because of the more sufficient decomposition and carbon activation at $800{ }^{\circ} \mathrm{C}$; however, it further decreased for the NPC-900, which can be attributed to the collapse of the micropores [38]. In addition, a large set of macropores were observed from SEM (Fig. 4). Therefore, the as-prepared NPC materials possessed a hierarchical porous structure containing micropores, mesopores, and macropores.

The morphology of as-prepared NPCs was detected using SEM analysis. As depicted in Fig. 4, the NPCs presented an interconnected porous network structure. As the pyrolysis temperature rose from 700 to $900{ }^{\circ} \mathrm{C}$, the etching of jackfruit rags became increasingly critical, so that the pore size grew larger and the surface became rougher. Particularly, the NPC-900 holes became channel-like; and this can explain the decrease in the specific surface area as the temperature increased from 800 to $900{ }^{\circ} \mathrm{C}$. The NPC-800 showed a large set of nanoscale pores, forming a 3D well-connected hierarchical porous structure (Fig. 4d). These hierarchical pores will serve as pathways for electrolyte permeation, shortening the diffusion, and transfer distance of sodium ions, thus favoring sodium storage performance.

Transmission electron microscopy analysis was performed to enable a clearer observation of the morphology 



Fig. 4 SEM images of a, b NPC-700, c, d NPC-800, and e, f NPC900

and structure. The TEM images of NPC-800 (Fig. 5a, b) demonstrate the NPC-800 particles were uneven and had a wrinkled hierarchical porous structure with open edges.
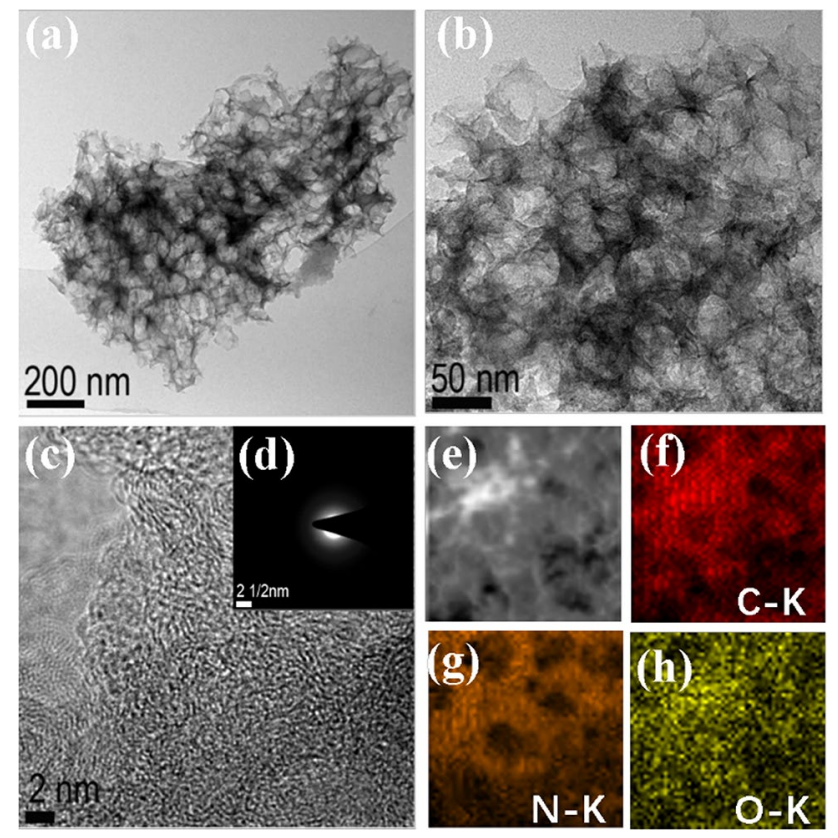

Fig. 5 a, b TEM images of NPC-800, $\mathbf{c}$ high-resolution TEM image of NPC-800, d the SAED pattern, e high-angle annular dark-field scanning TEM image, $\mathbf{f}$ the carbon, $\mathbf{g}$ nitrogen, and $\mathbf{h}$ oxygen elemental mappings in NPC-800
Furthermore, the images also reveal that NPC-800 was composed of morphological patterns of randomly stacked graphene analogous to carbon sheets (Fig. 5a, b). A closer inspection of NPC-800 using high-resolution TEM (Fig. 5c) showed graphene analogous layers, which featured a typical turbostratic carbon structure. The inset of Fig. 5c (Fig. 5d) is the selected area electron diffraction (SAED) pattern, which clearly revealed a weak crystallinity consistent with the XRD result. Moreover, elemental mapping showed that the elements of carbon $(\mathrm{C})$, nitrogen $(\mathrm{N})$, and oxygen $(\mathrm{O})$ were homogeneously distributed in the NPC-800 matrix (Fig. 5e-h). The simultaneous dopings of $\mathrm{N}$ and $\mathrm{O}$ may cause larger lattice spacing and more active sites for the accommodation of $\mathrm{Na}$ ions, resulting in better performance [39].

\section{Electrochemical Performance}

Type 2032 coin cells were assembled to evaluate the electrochemical performance of NPC in SIBs. Figure 6a displays the cyclic voltammetry (CV) curves of NPC-800 for the initial three cycles measured between 0.01 and $3.0 \mathrm{~V}$ with a scan rate of $0.1 \mathrm{mV} / \mathrm{s}$. In the first cathodic scan, a tremendous irreversible peak appeared at the potential of $0.85 \mathrm{~V}$, which may mostly have resulted from the irreversible reaction of the electrolyte with surface functional groups and the generation of a solid electrolyte interphase layer [40]. In addition, at a lower potential range of $0.01-0.2 \mathrm{~V}$, a pair
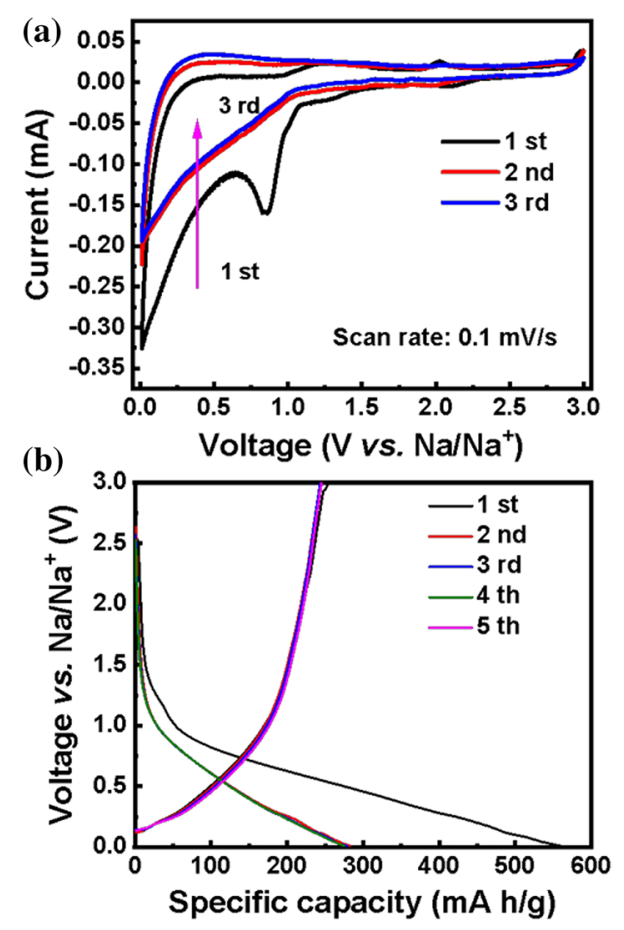

Fig. 6 a CV curves and b discharge-charge curves of NPC-800 
of sharp redox peaks, which corresponds to the insertion/ extraction of $\mathrm{Na}^{+}$in the NPC-800, were observed in the first cycle as well as subsequent cycles. Furthermore, a pair of weak redox peaks appeared at approximately $2.1 \mathrm{~V}$, which is ascribed to the surface redox reactions on the functionalized carbon electrode [41].

Figure $6 \mathrm{~b}$ shows the $1 \mathrm{st}, 2 \mathrm{nd}, 3 \mathrm{rd}, 4 \mathrm{th}$, and 5 th charge/ discharge profiles of NPC-800 at a constant current density of $100 \mathrm{~mA} / \mathrm{g}$. The initial discharge/charge curves presented a discharge and charge specific capacities of $559.6 \mathrm{~mA} \cdot \mathrm{h} / \mathrm{g}$ and $255.6 \mathrm{~mA} \cdot \mathrm{h} / \mathrm{g}$, respectively. According to the result, the initial coulombic efficiency was calculated to be $45.5 \%$. In the subsequent cycles, the coulombic efficiency ascended enormously to $87.3 \%$. The initial irreversible capacity loss was mainly due to the formation of a solid electrolyte interface layer and the irreversible trapping of $\mathrm{Na}$ ions in the porous structure [42].

Figure 7a shows that the NPCs samples delivered excellent cyclic stability at $100 \mathrm{~mA} / \mathrm{g}$ for 100 cycles. Among them, NPC-800 exhibited the best cyclic capacity performance; the sample retained a capacity of $235 \mathrm{~mA} \cdot \mathrm{h} / \mathrm{g}$ after 100 cycles $(180.6 \mathrm{~mA} \cdot \mathrm{h} / \mathrm{g}$ for NPC-700 and $156 \mathrm{~mA} \cdot \mathrm{h} / \mathrm{g}$ for NPC-900), corresponding to a capacity retention of $99.5 \%$. The rate capability of NPC-800 was tested at increased current densities ranging from 0.1 to $5 \mathrm{~A} / \mathrm{g}$ for ten cycles (Fig. 7b). As can be seen, the stabilized specific capacities were $306,251,195,156,130$, and $107 \mathrm{~mA} \cdot \mathrm{h} / \mathrm{g}$ at $0.1,0.2$, $0.5,1.0,2.0$, and $5.0 \mathrm{~A} / \mathrm{g}$, respectively. Thereafter, when the current density was set back to $0.1 \mathrm{~A} / \mathrm{g}$, the discharge capacity recovered to $268 \mathrm{~mA} \cdot \mathrm{h} / \mathrm{g}$, demonstrating excellent reversibility after the high-rate discharging and charging. Furthermore, the cycling performance of NPC-800 was further evaluated at $1 \mathrm{~A} / \mathrm{g}$ for 2000 cycles (Fig. 7c). A stable ultra-high reversible capacity of $122.3 \mathrm{~mA} \cdot \mathrm{h} / \mathrm{g}$ with an outstanding capacity retention of $99.1 \%$ was obtained, indicating the great potential of the NPC-800 for practical applications [43]. The EIS spectra (Fig. 7d) showed a decrease in $R_{\text {ct }}$ resistance, from $701 \Omega$ before cycling to $153 \Omega$ after cycling, for the tested 200 cycles, implying an increase in interfacial conductivity upon cycling. The inset of Fig. 7d shows an equivalent circuit according to the measured impedance. The reduction of resistance might be due to the enhanced electrolyte wetting of the material that increases the ionic conductivity [44].

\section{Conclusions}

In summary, hierarchical porous $\mathrm{N}$-doped carbon materials were synthesized from inexpensive, environmentally friendly jackfruit rags by a facile calcination process under argon atmosphere without any chemical or physical activation. The calcination temperature and resulting sample were systematically investigated. The hierarchical NPC obtained from jackfruit rags at $800{ }^{\circ} \mathrm{C}$ (NPC-800) possessed the best cycling performance and rate capability when used as the anode of SIBs. This excellent electrochemical performance can be attributed to the presence of the hierarchical porous structure and $\mathrm{N}$ doping of carbon. The outstanding $\mathrm{Na}$-ion storage performance combined with the sustainable
Fig. 7 a Cycling performances of NPC-700, NPC-800, and NPC-900 at a current density of $100 \mathrm{~mA} / \mathrm{g}$ between 0.005 and $3.0 \mathrm{~V}$ versus $\mathrm{Na} / \mathrm{Na}^{+}$, b rate performance of NPC-800, c long-term cycle life of NPC800 at a high current density of $1 \mathrm{~A} / \mathrm{g}$, and $\mathbf{d}$ impendence spectra of NPC-800 before and after cycling; inset is the equivalent circuit (a)

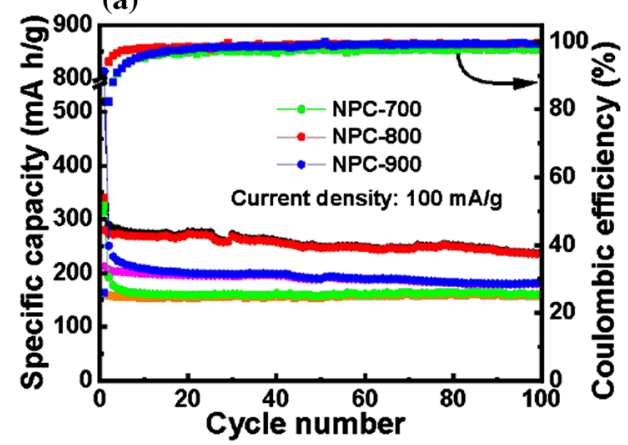

(c)

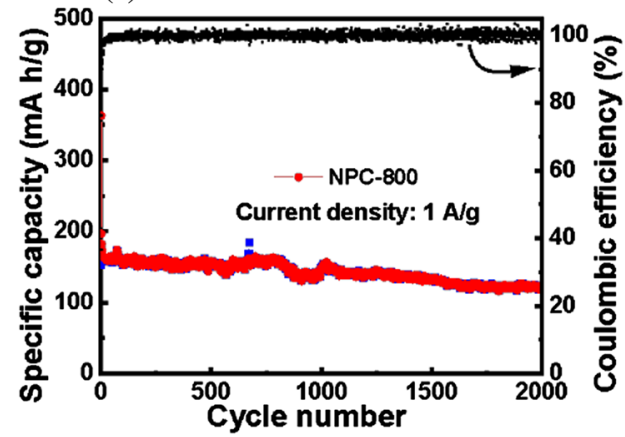

(b)

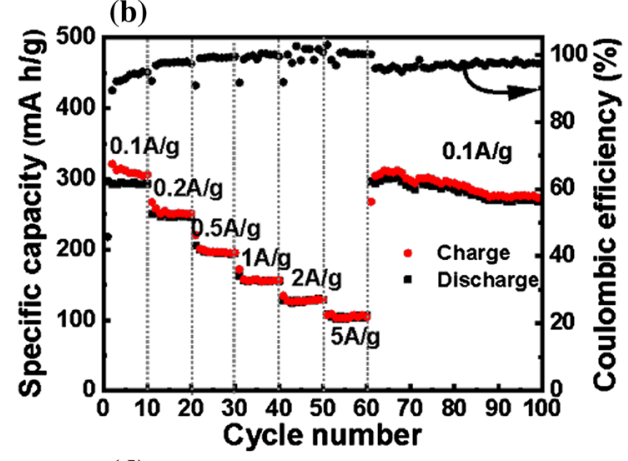

(d)

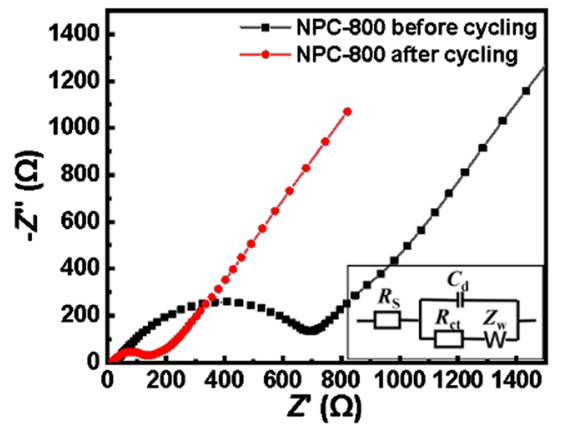


biomass source and scalable synthesis method makes jackfruit rags-derived NPC-800 a potential competitive SIBs anode material.

Acknowledgements This work was financially supported by National Natural Science Foundation of China (Nos. 21875253, 21703249) and the 1000 Plan Professorship for Young Talents.

Open Access This article is distributed under the terms of the Creative Commons Attribution 4.0 International License (http://creativeco mmons.org/licenses/by/4.0/), which permits unrestricted use, distribution, and reproduction in any medium, provided you give appropriate credit to the original author(s) and the source, provide a link to the Creative Commons license, and indicate if changes were made.

\section{References}

1. Shih CF, Zhang T, Li JH et al (2018) Powering the future with liquid sunshine. Joule 2(10):1925-1949

2. Chen X, Du Y, Zhang NQ et al (2012) 3D self-supported nanoarchitectured arrays electrodes for lithium-ion batteries. J Nanomater 2012:1-19

3. Tarascon JM, Armand M (2001) Issues and challenges facing rechargeable lithium batteries. Nature 414(6861):359-367

4. Liu K, Liu YY, Lin DC et al (2018) Materials for lithium-ion battery safety. Sci Adv 4(6):eaas9820. https://doi.org/10.1126/sciad v.aas 9820

5. Zhao R, Liang ZB, Zou RQ et al (2018) Metal-organic frameworks for batteries. Joule 2(11):2235-2259

6. Liang YL, Lai WH, Miao ZC et al (2018) Nanocomposite materials for the sodium-ion battery: a review. Small 14(5):1703951

7. Pan HL, Hu YS, Chen LQ (2013) Room-temperature stationary sodium-ion batteries for large-scale electric energy storage. Energy Environ Sci 6(8):2338-2361

8. Liu TF, Zhang YP, Jiang ZG et al (2019) Exploring competitive features of stationary sodium ion batteries for electrochemical energy storage. Energy Environ Sci 12(5):1512-1533

9. Ben YM, Vergnet J, Saubanere M et al (2019) Unified picture of anionic redox in Li/Na-ion batteries. Nat Mater 18(5):496-502

10. Yao XH, Ke YJ, Ren WH et al (2019) Defect-rich soft carbon porous nanosheets for fast and high-capacity sodium-ion storage. Adv Energy Mater 9(6): 1803260

11. Kong DB, Gao Y, Xiao ZC et al (2018) Rational design of carbonrich materials for energy storage and conversion. Adv Mater. https ://doi.org/10.1002/adma.201804973

12. Hou HS, Qiu XQ, Wei WF et al (2017) Carbon anode materials for advanced sodium-ion batteries. Adv Energy Mater 7:1602898

13. Li YM, Xu SY, Wu XY et al (2015) Amorphous monodispersed hard carbon micro-spherules derived from biomass as a high performance negative electrode material for sodium-ion batteries. J Mater Chem A 3(1):71-77

14. Hu XD, Sun XH, Yoo SJ et al (2019) Nitrogen-rich hierarchically porous carbon as a high-rate anode material with ultra-stable cyclability and high capacity for capacitive sodium-ion batteries. Nano Energy 56:828-839

15. Mao YJ, Chen YT, Qin J et al (2019) Capacitance controlled, hierarchical porous 3D ultra-thin carbon networks reinforced Prussian blue for high performance Na-ion battery cathode. Nano Energy 58:192-201
16. Vadahanambi S, Chun HH, Jung KH et al (2016) Nitrogen doped holey carbon nano-sheets as anodes in sodium ion battery. RSC Adv 6(44):38112-38116

17. Fu LJ, Tang K, Song KP et al (2014) Nitrogen doped porous carbon fibres as anode materials for sodium ion batteries with excellent rate performance. Nanoscale 6(3):1384-1389

18. Wang L, Yang CL, Dou S et al (2016) Nitrogen-doped hierarchically porous carbon networks: synthesis and applications in lithium-ion battery, sodium-ion battery and zinc-air battery. Electrochim Acta 219:592-603

19. Yang YR, Qiu M, Liu L et al (2016) Nitrogen-doped hollow carbon nanospheres derived from dopamine as high-performance anode materials for sodium-ion batteries. Nano 11(11):1650124

20. Zhang KL, Li XN, Liang JW et al (2015) Nitrogen-doped porous interconnected double-shelled hollow carbon spheres with high capacity for lithium ion batteries and sodium ion batteries. Electrochim Acta 155:174-182

21. Liu H, Jia MQ, Sun N et al (2015) Nitrogen-rich mesoporous carbon as anode material for high-performance sodium-ion batteries. ACS Appl Mater Interfaces 7(49):27124-27130

22. Correa C, Kruse A (2018) Biobased functional carbon materials: production, characterization, and applications - a review. Materials 11(9):1568

23. Jiang LL, Sheng LZ, Fan ZJ (2018) Biomass-derived carbon materials with structural diversities and their applications in energy storage. Sci China Mater 61(2):133-158

24. Kim MJ, Park JE, Kim S et al (2019) Biomass-derived air cathode materials: pore-controlled S, N-Co-doped carbon for fuel cells and metal-air batteries. ACS Catal 9:3389-3398

25. Zeng G, Zhou BL, Yi LC et al (2018) Green and facile fabrication of hierarchical $\mathrm{N}$-doped porous carbon from water hyacinths for high performance lithium/sodium ion batteries. Sustain Energy Fuels 2(4):855-861

26. Chaudhari NK, Bhattacharjya D, Kim H et al (2017) N-carbon from waste tea as efficient anode electrode material in lithium ion batteries. J Nanosci Nanotechnol 17(3):1838-1846

27. Qin DC, Liu ZY, Zhao YZ et al (2018) A sustainable route from corn stalks to N, P-dual doping carbon sheets toward high performance sodium-ion batteries anode. Carbon 130:664-671

28. Shen F, Zhu HL, Luo W et al (2015) Chemically crushed wood cellulose fiber towards high-performance sodium-ion batteries. ACS Appl Mater Interfaces 7(41):23291-23296

29. Zou GQ, Huang ZD, Zhao GG et al (2017) Evaluating the storage behavior of superior low-cost anode material from biomass for high-rate sodium-ion batteries. J Electrochem Soc 164(7):A1431-A1437

30. Zhang N, Liu Q, Chen WL et al (2018) High capacity hard carbon derived from Lotus stem as anode for sodium ion batteries. J Power Sources 378:331-337

31. Wang PZ, Zhu XS, Wang QQ et al (2017) Kelp-derived hard carbons as advanced anode materials for sodium-ion batteries. J Mater Chem A 5(12):5761-5769

32. Qian WJ, Sun FX, Xu YH et al (2014) Human hair-derived carbon flakes for electrochemical supercapacitors. Energy Environ Sci 7(1):379-386

33. Sheesley RJ, Schauer JJ, Chowdhury Z et al (2003) Characterization of organic aerosols emitted from the combustion of biomass indigenous to South Asia. J Geophys Res. 108(D9):4285. https:// doi.org/10.1029/2002jd002981

34. Zheng XY, Luo JY, Lv W et al (2015) Two-dimensional porous carbon: synthesis and ion-transport properties. Adv Mater 27(36):5388-5395

35. Tan X, Huang XS, Zou YL et al (2018) Synthesis and characterization of Co-doped brookite titania photocatalysts with high photocatalytic activity. Trans Tianjin Univ 24(2):111-122 
36. Guo SC, Hu X, Hou Y et al (2017) Tunable synthesis of yolk-shell porous silicon@carbon for optimizing Si/C-based anode of lithium-ion batteries. ACS Appl Mater Interfaces 9(48):42084-42092

37. $\mathrm{Xu} \mathrm{FY,} \mathrm{Na} \mathrm{P} \mathrm{(2018)} \mathrm{String} \mathrm{and} \mathrm{ball-like} \mathrm{TiO}_{2} / \mathrm{rGO}$ composites with high photo-catalysis degradation capability for methylene blue. Trans Tianjin Univ 24(3):272-281

38. Li ZJ, Lv W, Zhang C et al (2015) A sheet-like porous carbon for high-rate supercapacitors produced by the carbonization of an eggplant. Carbon 92:11-14

39. Hu X, Jia JC, Wang GX et al (2018) Reliable and general route to inverse opal structured nanohybrids of carbon-confined transition metal sulfides quantum dots for high-performance sodium storage. Adv Energy Mater 8(25):1801452

40. Jin RC, Meng M, Zhang SH et al (2018) CNTs@C@ $\mathrm{Cu}_{2-x} \mathrm{Se}$ hybrid materials: an advanced electrode for high performance lithium batteries and supercapacitors. Energy Technol 6(11):2179-2187
41. Zhao WX, Ci SQ, Hu X et al (2019) Highly dispersed ultrasmall $\mathrm{NiS}_{2}$ nanoparticles in porous carbon nanofiber anodes for sodium ion batteries. Nanoscale 11(11):4688-4695

42. Hu X, Liu YJ, Chen JX et al (2019) FeS quantum dots embedded in 3D ordered macroporous carbon nanocomposite for highperformance sodium-ion hybrid capacitors. J Mater Chem A 7(3):1138-1148

43. Wang FM, Liu MC, Zhang XB et al (2018) In situ growth of 3D hierarchical ZnO@ $\mathrm{Ni}_{x} \mathrm{Co}_{1-x}(\mathrm{OH})_{y}$ core/shell nanowire/nanosheet arrays on $\mathrm{Ni}$ foam for high-performance aqueous hybrid supercapacitors. Trans Tianjin Univ 24(3):201-211

44. Wang Y, Wang CY, Guo HN et al (2017) A nitrogen-doped threedimensional carbon framework for high performance sodium ion batteries. RSC Adv 7(3):1588-1592 